\title{
Sociodemographic and physical predictors of non-participation in community based physical checkup among older neighbors: a case-control study from the Kyoto-Kameoka longitudinal study, Japan
}

Miwa Yamaguchi ${ }^{{ }^{*+}}$, Tsukasa Yoshida ${ }^{1,2+}$, Yosuke Yamada ${ }^{1,3,4}$, Yuya Watanabe ${ }^{3,5,6}$, Hinako Nanri ${ }^{1,6}$, Keiichi Yokoyama ${ }^{4}$, Heiwa Date ${ }^{7}$, Motoko Miyake ${ }^{6}$, Aya Itoi $^{8}$, Emi Yamagata ${ }^{9}$, Taeko Masumoto ${ }^{9}$, Yasuko Okayama ${ }^{9}$, Yasuko Yoshinaka ${ }^{4}$, Misaka Kimura ${ }^{3,6^{*}}$ and Kyoto-Kameoka study group

\begin{abstract}
Background: It is difficult to obtain detailed information on non-participants in physical and health examination checkups in community-based epidemiological studies. We investigated the characteristics of non-participants in a physical and health examination checkup for older adults in a nested study from the Japanese Kyoto-Kameoka Longitudinal Study.

Methods: We approached a total of 4831 people aged $\geq 65$ years in 10 randomly selected intervention regions. Participants responded to a mail-based population survey on needs in the sphere of daily life to encourage participation in a free face-to-face physical checkup examination; 1463 participants (706 men, 757 women) participated in the physical checkup. A multiple logistic regression model was performed to investigate the adjusted odds ratios (aOR) of nonparticipation based on sociodemographic status apart from psychological and physiological frailty as assessed by the validated Kihon Checklist.

Results: There was a significant, inverse relationship between non-participation and frequently spending time alone among individuals who lived with someone or other family structure ( $\mathrm{aOR}=0.53$, standard error [SE] 0.08 in men, $\mathrm{aOR}=0.66$, SE 0.09 in women). Very elderly (over 80 years old) women, poorer health consciousness and current smoking in both sexes and poor self-rated health in men, were significantly related to higher non-participation rates. In both sexes, individuals who did not participate in community activities were significantly more likely to be non-participants than individuals who did (aOR=1.94, SE 0.23 in men, aOR = 3.29, SE 0.39 in women). Having low IADL and physical functioning scores were also associated with higher rates of non-participation.

\footnotetext{
* Correspondence: yamaguchi3005@gmail.com; misaka@kyotogakuen.ac.jp

${ }^{\dagger}$ Equal contributors

'Department of Nutrition and Metabolism, National Institutes of Biomedical

Innovation, Health and Nutrition, Tokyo 162-8636, Japan

${ }^{3}$ Laboratory of Applied Health Sciences, Kyoto Prefectural University of

Medicine, Kyoto 602-8566, Japan

Full list of author information is available at the end of the article
}

(c) The Author(s). 2018 Open Access This article is distributed under the terms of the Creative Commons Attribution 4.0 International License (http://creativecommons.org/licenses/by/4.0/), which permits unrestricted use, distribution, and reproduction in any medium, provided you give appropriate credit to the original author(s) and the source, provide a link to the Creative Commons license, and indicate if changes were made. The Creative Commons Public Domain Dedication waiver (http://creativecommons.org/publicdomain/zero/1.0/) applies to the data made available in this article, unless otherwise stated. 
(Continued from previous page)

Conclusion: Health consciousness and lack of community activity participation were predictors of non-participation in a physical checkup examination among older adults. In addition, lower IADL and physical functioning/strength were also predictors of non-participation.

On the contrary, older inhabitants living with someone tended to participate in the physical checkup examination for social interchange when they were frequently alone in the household. This study suggests the importance of considering aging especially for women and poor sociodemographic background and physical frailty for both sexes so that older people can access health programs without difficulty.

Trial registration: UMIN000008105. Registered 26 April 2012. Retrospectively registered.

Keywords: Physical activity program, Sociodemographic factors, Physical frailty, Participation rate, Community-dwelling older people, Health promotion, Case-control study

\section{Background}

In 2014, the life expectancy at birth was on average 86 . 8 years for women and 80.5 years for men in Japan [1]. In line with the fact that Japanese life expectancy is the highest in the world, the total amount of nursing care costs in fiscal year 2013 was 9.2 trillion yen ( 81 billion USD), due to the aging of Japanese society [1]. The Japanese government encouraged the promotion of community based multi-faceted approaches to prevent longterm care in the Integrated Community Care System [2].

The importance of lifestyle interventions in preventing long-term care is well-known [3-5]. Several studies investigating life-style interventions for independent life for older people have reported positive effects on physical ability [6-8], well-being [7, 9], and mental well-being [9]. A previous article reported that a lifestyle-based physical activity program resulted in a 640.4 USD/year lower cost of total medical expenditure in the intervention group as compared to the control group [10]. However, one review article indicated that the initial participation level in physical activity programs for people aged 55 years or older ranged from merely 1.4 to $16.2 \%$ (mean $=9.2 \%$ ), among five programs with durations ranging 1 to 6 months [11]. Another review article indicated that the very elderly, older people from black and minority ethnic groups, and older people living in deprived areas encountered barriers to being recruited for and engaging in health promotion interventions and related research [12, 13]. One previous Japanese study provided evidence that non-regular participants who attended a sports group once or twice a month, a few times a year, or never were more likely to have certain sociodemographic (i.e., lower educational level, being employed, and having worked primarily in the agricultural/forestry/fishery industry) and biopsychosocial characteristics (i.e., poor self-rated health and depression) [14]. Therefore, it is important to consider social and environmental support so that older people can engage in health promotion interventions $[3,5,13]$. However, previous reviews have indicated that there is still no high-quality evidence regarding the effectiveness of different approaches for older people who experience barriers to enrolling in health programs, including those in Japan $[5,13]$. We hypothesize that poor sociodemographic, physical, and psychological factors may discourage older inhabitants from participating in community-based health programs. Thus, we examined the characteristics of non-participants compared with participants in the intervention program, including sociodemographic, physical, and psychological factors in community-based health programs in Japan.

\section{Methods \\ Study participants}

Kameoka city is located in the central area of Kyoto Prefecture, about $25 \mathrm{~km}$ west of Kyoto City (Fig. 1) [15]. The Kyoto-Kameoka Longitudinal Study in the city has been described previously [16]. This study has been conducted since July $29^{\text {th }}, 2011$ with the Needs in the Sphere of Daily Life (NSDL) survey created by the national government's Ministry of Health, Labour and Welfare, modified for the present study [16], as a baseline (Fig. 2). The NSDL survey was given to 16,474 people aged 65 years or older without indication of long-term care need that was registered by the city office. From the 12,054 responders, the research office formally mailed an invitation for a free physical checkup examination in February $14^{\text {th }}, 2012$ to the 4831 responders ( 28 of 4859 residents died before the physical checkup) who lived in 10 randomly selected intervention regions, from a total of 21 regions. The physical checkup was a one to three-day event in each region at the community center, depending on the region's population, as part of the population-based comprehensive geriatric intervention program for preventing long-term care. The flyer described the checkup duration (approximately one hour of total) and measurement items to assess their mobility ability and fitness, including: right front thigh muscle thickness, grip strength, maximum isometric right knee extension strength, and their usual and maximum physical functions. After the invitation, 1463 participants (participation rates $31.6 \%$ in men, $28.9 \%$ in 


\section{Kameoka City in Kyoto Prefecture}

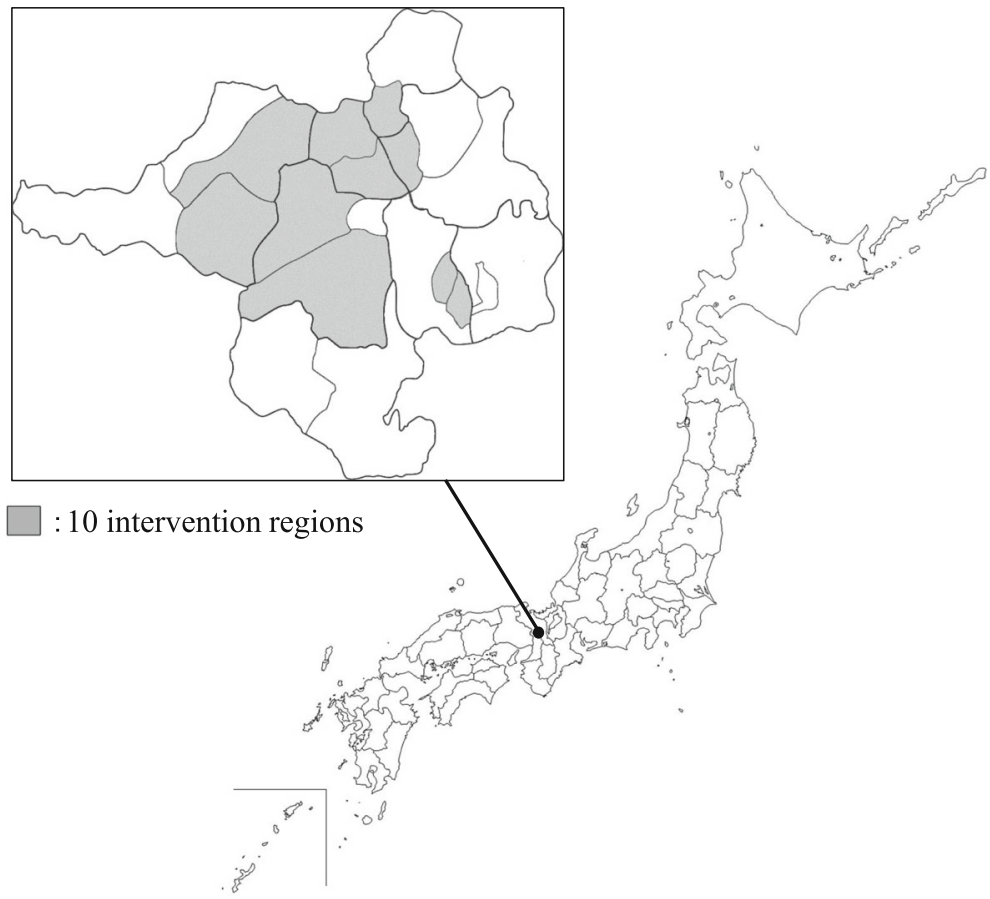

Fig. 1 Geographical features of Kameoka city, Kyoto Prefecture, Japan

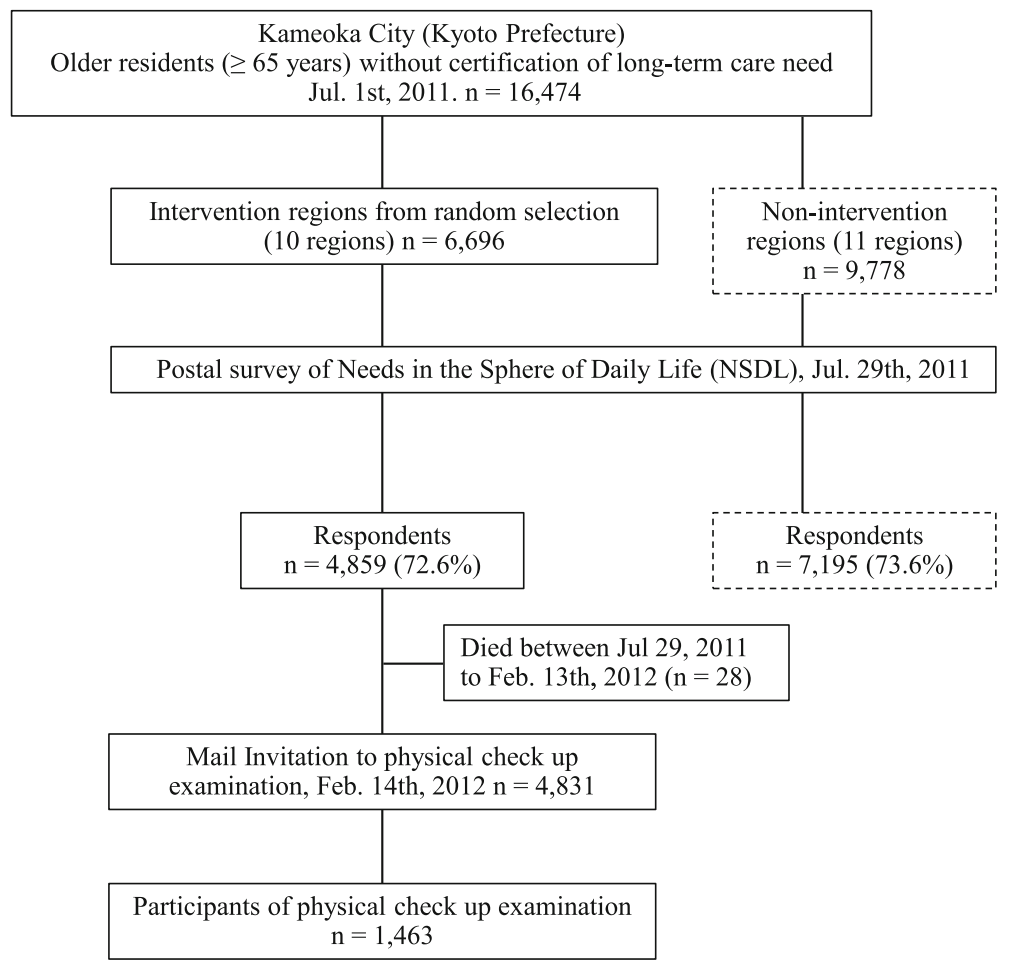

Fig. 2 Flow chart of the physical checkup in the Kyoto-Kameoka study 
women) voluntarily participated in the physical checkup. Considering the distribution, age-adjusted participation rates were $31.8 \%$ in men and $27.4 \%$ in women, calculated by multiplying crude participation rates and the population of Kameoka city (taken from the population statistics in July $1^{\text {st }}, 2011[17,18]$ among each age category (65-69, 70-74, 75-79, and $\geq 80$ years) in men and women. Therefore, the final sample comprised 3368 people (1509 men, 1859 women) in the case group of non-participants in the physical checkup, and 1463 participants (706 men, 757 women) in the control group who did participate.

\section{Explanatory variables}

Sociodemographic variables proposed to be social determinants of health were employed as explanatory variables from the self-reported questionnaire (Additional file 1: Table S1) [18]. First, age, calculated from the resident's date of birth registered in the city office, was classified into bins of $65-69,70-74,75-79$, and $\geq 80$ years. Social status variables included family structure (with someone or others / living alone), living with spouse (yes / no), alone at home: spending a day at home alone all day (rarely / frequently), and educational attainment $(\geq 13,10-12$, or $\leq 9$ years). The questions regarding "living with spouse" and "alone at home" were only for people who reported living with someone or others. Here in Japan, most citizens can receive the National Pension (basic pension) after they turn 65 years old. According to their occupations, residents are classified into three levels of the National Pension: Category 1 is for residents aged 20 to 59 years who are not Category 2 or 3 insured persons (e.g., selfemployed persons, farmers, or students); Category 2 combines Employees' Pension Insurance for private company workers or Mutual Aid Pension for public employees and private school teachers and employees with the basic pension; and Category 3 is for dependents of the spouse who belongs to insured Category 2 [19]. In this study, we grouped pension levels into three categories: the National Pension (Category 1), the Employees' Pension (Categories 2 and 3), and no pension or other pensions. Other economic variables examined included (subjective) economic difficulty (yes / no), current employment (working / not working), and automobile access (yes / no). Health-related questions included: interest in health topics (yes / no), self-rated health (good / poor), and smoking status (never, past, and current). To assess whether an individual participates in community activities, we coded this variable as "yes" when residents answered affirmatively to participating in at least one of the following activities: local events (e.g., festivals and dances), community associations, hobby activity groups, senior citizen clubs, volunteer groups, and other groups. Population density (city $\geq 1000 /$ province $<1,000$ people $/ \mathrm{km}^{2}$ ) was also assessed.

\section{Assessment of frailty by the Kihon checklist}

The Kihon Checklist (KCL) is a well-validated tool for the screening of long-term care needs for communitydwelling older residents who have difficulties with selfsupport. In Japan, the KCL has being widely used to assess frailty [20, 21]. The KCL consists of 25 items and has seven sections. A total KCL score of $\geq 7$ points was defined as suggesting frailty and a high risk of needing long-term care (Additional file 2: Table S2). Each of the seven sections of KCL also have cut-off points for assessing frailty based on norms proposed by previous reports [22-24]: $\geq 3$ for instrumental activities of daily living (IADL), $\geq 3$ for physical function/strength, 2 for malnutrition, $\geq 2$ for oral function, $\geq 1$ for socialization (being housebound), $\geq 1$ for memory, and $\geq 2$ for mood.

\section{Statistical analysis}

To analyze differences in the characteristics of nonparticipation versus participation in the physical checkup, we used a chi-square test for categorical variables. In consideration of the gender difference in participation rates, we analyzed separately by gender. We also estimated the adjusted odds ratios (aOR) and 95\% confidence intervals (CI) for non-participation using a multiple logistic regression model. Possible sociodemographic factors for non-participation of health checkup were extracted: age $(65-69,70-74,75-79$, and $\geq 80$ years), social status (family structure, living with spouse, alone at home, and educational attainment), economic status (economic difficulty, pension, current employment, and automobile access), health conscious (interest in health topics, self-rated health, and smoking status), community activities (yes / no), and population density (city / province). In Model 1, analyses for each variable were adjusted for all sociodemographic variables we collected. In Model 2, the total score for the KCL was added to Model 1 . The association of nonparticipation with seven types of frailty (IADL, function/ strength, malnutrition, oral function, socialization, memory, and mood) was analyzed in addition to the total KCL score. In the analysis with the KCL score, Model 1 was adjusted for all sociodemographic variables. The seven types of KCL were added to Model 1 in Model 2, in order to investigate which types were primarily associated with non-participation. All extracted factors were categorical variables. We used unknown (missing) variables including either merely missing or "no response," purposefully. The variables estimated the aORs of nonparticipation in each sociodemographic status and frailty level to compare better sociodemographic status and lower frailty levels as the reference groups. Calculations and statistical tests were performed using the STATA software, version 14.0 (StataCorp LP, College Station, 
TX). All statistical tests were 2 -sided and $p$-values $<0.05$ were considered statistically significant.

\section{Results}

As can be seen in Table 1, the proportion of nonparticipation in women was higher than men (non-participation $1509,68.1 \%$ in men; $1859,71.1 \%$ in women). The proportions of non-participation of those in lower socioeconomic groups had a tendency to be higher than that of those in the higher socioeconomic groups (Table 1).

As shown in Table 2, older adults with higher total and sub-score KCL, defined frailty, were more likely to be non-participants, regardless of sex (Table 2).

Tables 3 and 4 show the adjusted odds ratios for nonparticipation per sociodemographic status among men and women, respectively. First, 75-79-year-old men had a significantly lower aOR of non-participation compared to that of the lowest age group (65-69 years) in the fully adjusted Model 2 (Table 3). Among men, we observed significant, inverse associations between 'frequent' group in the alone at home and non-participation, as compared to 'rarely' group ( $\mathrm{aOR}=0.53,95 \% \mathrm{CI}$ : $0.40,0.70)$ (Table 3 ). Individuals with $\leq 9$ years of educational attainment were more likely to be non-participants (aOR $=1.52,95 \%$ CI: 1 . $15,2.01)$ compared those with $\geq 13$ years. In terms of significant economic predictors, being on 'the National Pension' compared to 'the Employees' Pension' and 'No' group of automobile access indicated more likely to be a nonparticipant $(\mathrm{aOR}=1.30,95 \% \mathrm{CI}: 1.04,1.63$ in the National Pension; aOR $=1.32,95 \% \mathrm{CI}: 1.00,1.74$ in automobile access). Having lower levels of all three types of health consciousness showed significantly positive associations with non-participation $(\mathrm{aOR}=1.69,95 \% \mathrm{CI}$ : 1.23, 2.33 for 'No' of interest in health topics; aOR $=1.68,95 \% \mathrm{CI}: 1.27,2.22$ for 'poor' in self-rated health; $\mathrm{aOR}=1.62,95 \% \mathrm{CI}: 1.19,2$. 21 for 'current' in smoking status). Individuals who were not engaged in community activities, 'No' group, were more likely to be non-participants, compared to than those who did not engage in any such activities $(\mathrm{aOR}=1$. 94, 95\% CI: 1.54, 2.44).

Whereas in women, higher age-groups ( $\geq 80$ years) had a significantly higher aOR of non-participation compared to that of the lowest age group in Model 2 (Table 4). The 'alone' in family structure showed an inverse association of non-participation than 'with someone or others', but not significant (aOR $=0.78,95 \%$ CI: 0 . $60,1.01$ ) (Table 4). The aOR of non-participation for individuals who responded with 'frequently' to living alone at home was significantly lower than those who responded with 'rarely' (aOR $=0.67,95 \% \mathrm{CI}$ : 0.50, 0.88). Having no interest in health topics and current smoking status in health conscious both exhibited a positive relationship to non-participation, compared to health topics interest and having never smoked $(\mathrm{aOR}=1.78,95 \% \mathrm{CI}$ : $1.09,2.93$ in 'No' of interest in health topics; $\mathrm{aOR}=2.71$, 95\% CI: 1.50, 4.90 in 'current' of smoking status). The non-engagement in community activities, 'No' group, showed a positive relationship with non-participation, compared to the engagement group $(\mathrm{aOR}=3.30,95 \%$ CI: 2.62, 4.15).

Following results suggesting an association between frailty assessed by KCL and non-participation among men (see Table 5) and women (see Table 6), lower level of IADL and physical function/strength were positively associated with non-participation than higher levels in both men and women (men $[\mathrm{IADL}] \mathrm{aOR}=1.35,95 \% \mathrm{CI}$ : $1.01,1.82$; [physical function/strength] aOR $=1.40,95 \% \mathrm{CI}: 1.03,1$. 91; women [IADL] aOR $=2.42,95 \%$ CI: 1.60, 3.64; [physical function/strength] aOR $=1.36,95 \%$ CI: 1.07, 1.73) (Tables 5 and 6). In Model 2, these associations remained significant even after adjusting for all KCL items, with the exception of IADL among men. Furthermore, the higher level of socialization in men showed a significant, inverse association with non-participation $(\mathrm{aOR}=0.76,95 \% \mathrm{CI}: 0$. 60, 0.96).

The high significant odds ratios for non-participation were observed on unknown variables concerning living with a spouse among both genders educational attainment for men; KCL mood subscore in Model 1 for men; and KCL malnutrition subscore in Model 1 for women, and a negative association with unknown variables was observed in "alone at home" for men. The results excluding unknown variables were not different in the current results with unknown variables but were statistically unclear in some part of the results (data not shown).

\section{Discussion}

To our knowledge, only a few studies have examined what characteristics distinguish non-participants in faceto-face health and physical checkup due to the of lack of detailed data on non-participants. We found that older Japanese adults who were non-participants in a community conducted physical checkup had poorer sociodemographic backgrounds, in addition to greater frailty as indicated by the IADL and physical functioning/strength and aging in women. Specifically, an increase in each of the following factors was linked to a $1.32-3.30$-fold increase of non-participation: (for men) lower educational attainment, being on the National Pension (versus the Employees' Pension), lack of automobile access, poor self-rated health; (for both sexes) no interest in health topics, current smoking, and lack of participation in community activities. On the other hand, for both sexes spending alone at home frequently while living with someone or other family structure was associated with a 0.53-0.67-fold decrease in non-participation was compared to those who were rarely alone at home. 
Table 1 Sociodemographic characteristics of physical checkup non-participants and participants among Japanese older men and women

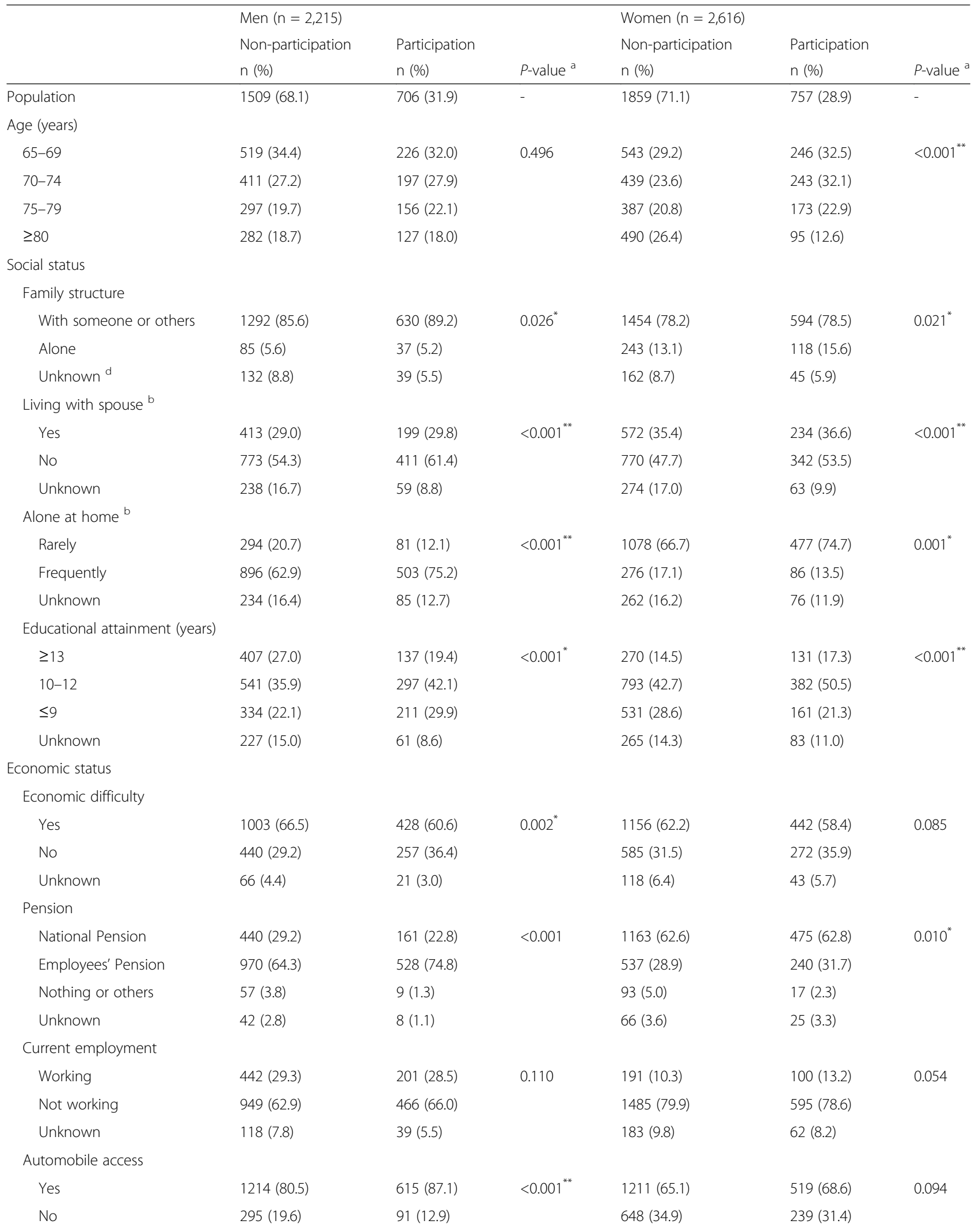


Table 1 Sociodemographic characteristics of physical checkup non-participants and participants among Japanese older men and women (Continued)

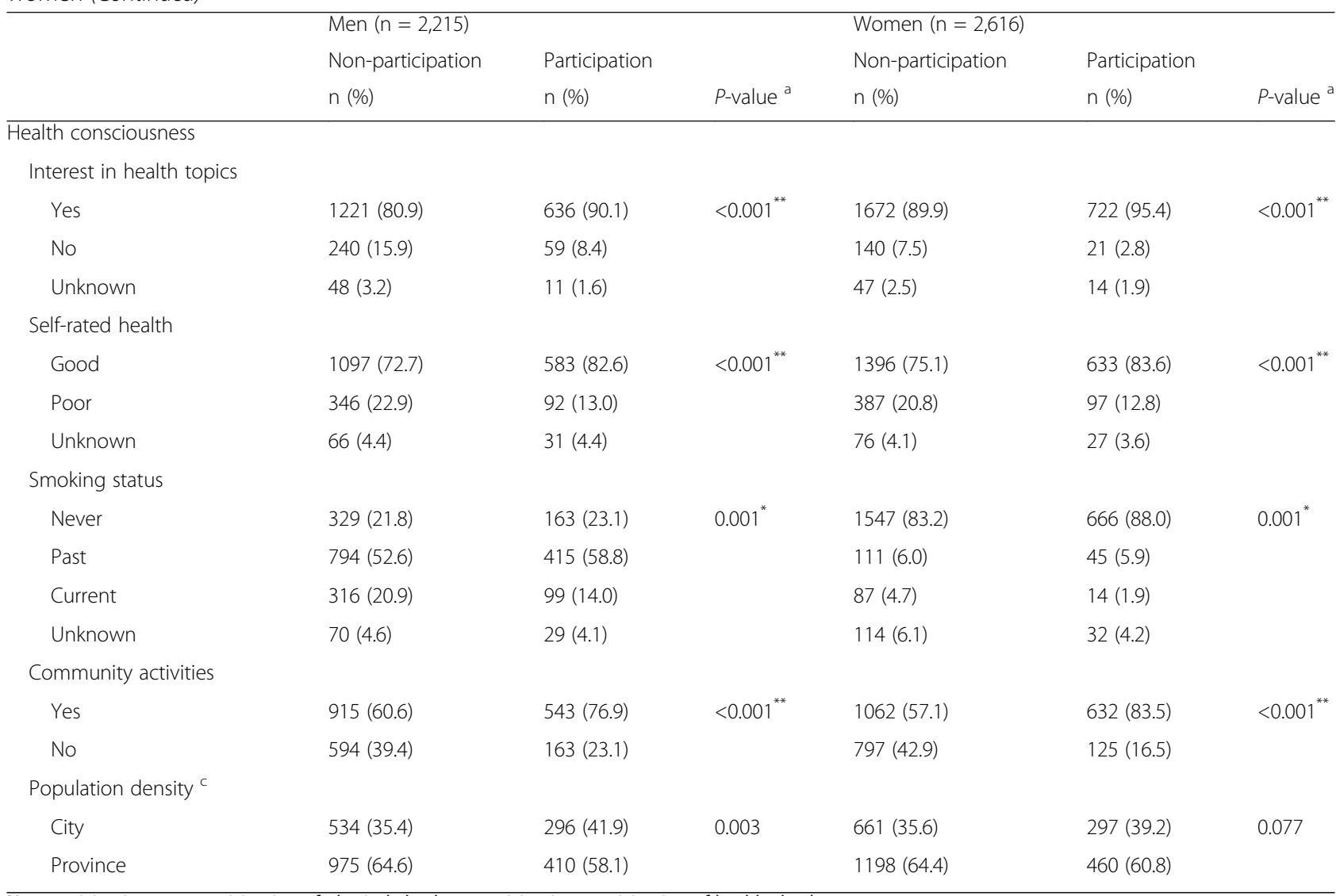

Non-participation, non-participation of physical checkup; participation, participation of health checkup

${ }^{*} p$-value $<0.05,{ }^{* *} p$-value $<0.001$

${ }^{a}$ Chi-square test was performed for categorical variables

${ }^{\mathrm{b}}$ These results were indicated among those who were 'living with someone or others' in the family structure (non-participation 1,424 in men, 1,616 in women; physical checkup 669 in men, 639 in women)

'Population density (people/ $\left.\mathrm{km}^{2}\right)$ was categorized as city $(\geq 1,000)$ and province $(<1,000)$

${ }^{\mathrm{d}}$ All unknown (missing) variables were included either merely missing or "no response" on purpose

Furthermore, when IADL and physical functioning/ strength were at a low/impaired level, the odds ratio of non-participation indicated a 1.35-2.42-fold increase compared to those who were at a higher/less impaired level, for both sexes.

To assess consistency, our current findings were compared with other previous research. The overall participation rates were higher in the current study $(31.9 \%$ in men, $28.9 \%$ in women) as compared to rates in five similar studies (range 1.4-16.2\%) reported from the previous review [11]. In our study, all individuals eligible to participate in the checkup had already responded to a mail survey at baseline, which may have driven our relatively higher participation rates [11].

Interestingly, we found that when individuals living with someone or other family structure were nevertheless often alone at home, these individuals were in fact relatively more likely to attend the physical checkup. One reason cohabiting individuals who nevertheless spend much time alone might attend the checkup would be for social exchange and conversation with neighbors or staff. It should also be noted that the opportunity to participate in physical checkups may help individuals who were low in socialization to go outside. The physical checkup is expected to be a significant opportunity for social exchange and preventing the situation of being housebound among older residents.

The current results were in the line with the previous research observing an association between poor socioeconomic status and non-participation in health programs and health checkups in middle age and older populations $[14,25-27]$. For instance, lower educational attainment has been consistently found to predict non-participation in sports groups among Japanese older people [14]. While, a previous study was no association between educational level and participation in a health checkup for Germans aged 35 years or older [27]. The relatively large number of women with low educational attainments in our study 
Table 2 Kihon Checklist scores among physical checkup non-participants and participants among Japanese older men and women

\begin{tabular}{|c|c|c|c|c|c|c|}
\hline \multirow[b]{2}{*}{ Kihon Checklist } & \multicolumn{3}{|l|}{ Men } & \multicolumn{3}{|l|}{ Women } \\
\hline & $\begin{array}{l}\text { Non-participation } \\
\text { n (\%) }\end{array}$ & $\begin{array}{l}\text { Participation } \\
\text { n (\%) }\end{array}$ & $P$-value ${ }^{a}$ & $\begin{array}{l}\text { Non-participation } \\
\text { n (\%) }\end{array}$ & $\begin{array}{l}\text { Participation } \\
\text { n (\%) }\end{array}$ & $P$-value ${ }^{a}$ \\
\hline \multicolumn{7}{|l|}{ Total score } \\
\hline$<7$ & $671(44.5)$ & $390(55.2)$ & $<0.001^{* *}$ & $725(38.9)$ & $413(54.6)$ & $<0.001^{* *}$ \\
\hline$\geq 7$ & $343(22.7)$ & $148(21.0)$ & & $470(25.2)$ & $128(16.9)$ & \\
\hline Unknown ${ }^{b}$ & $495(32.8)$ & $169(23.8)$ & & $671(36.0)$ & $216(28.5)$ & \\
\hline \multicolumn{7}{|l|}{ IADL } \\
\hline$<3$ & $1102(73.0)$ & $603(85.4)$ & $<0.001^{* *}$ & $1406(75.4)$ & $694(91.7)$ & $<0.001^{* *}$ \\
\hline$\geq 3$ & $311(20.6)$ & $79(11.2)$ & & $313(16.8)$ & $31(4.1)$ & \\
\hline Unknown & $96(6.4)$ & $24(3.4)$ & & $147(7.9)$ & $32(4.2)$ & \\
\hline \multicolumn{7}{|c|}{ Physical function/strength } \\
\hline$<3$ & $1075(71.2)$ & $576(81.6)$ & $<0.001^{* *}$ & $1075(57.6)$ & $539(71.2)$ & $<0.001^{* *}$ \\
\hline$\geq 3$ & $262(17.4)$ & $74(10.5)$ & & $561(30.1)$ & $139(18.4)$ & \\
\hline Unknown & $172(11.4)$ & $56(7.9)$ & & $230(12.3)$ & $79(10.4)$ & \\
\hline \multicolumn{7}{|l|}{ Malnutrition } \\
\hline$<2$ & $1225(81.2)$ & $619(87.7)$ & $<0.001^{* *}$ & 1467 (78.6) & $648(85.6)$ & $<0.001^{* *}$ \\
\hline 2 & $36(2.4)$ & $11(1.6)$ & & $41(2.2)$ & $14(1.9)$ & \\
\hline Unknown & $248(16.4)$ & $76(10.8)$ & & $358(19.2)$ & 95 (12.6) & \\
\hline \multicolumn{7}{|l|}{ Oral function } \\
\hline$<2$ & $1048(69.5)$ & $530(75.1)$ & $0.010^{*}$ & $1312(70.3)$ & $576(76.1)$ & $0.003^{*}$ \\
\hline$\geq 2$ & $377(25.0)$ & $152(21.5)$ & & $438(23.5)$ & 154 (20.3) & \\
\hline Unknown & $84(5.6)$ & $24(3.4)$ & & $116(6.2)$ & $27(3.6)$ & \\
\hline \multicolumn{7}{|l|}{ Socialization } \\
\hline$<1$ & 960 (63.6) & 479 (67.9) & 0.075 & 996 (53.4) & $512(67.6)$ & $<0.001^{* *}$ \\
\hline$\geq 1$ & $487(32.3)$ & $208(29.5)$ & & $793(42.5)$ & $225(29.7)$ & \\
\hline Unknown & $62(4.1)$ & $19(2.7)$ & & $77(4.1)$ & $20(2.6)$ & \\
\hline \multicolumn{7}{|l|}{ Memory } \\
\hline$\geq 1$ & 780 (51.7) & $434(61.5)$ & $<0.001^{* *}$ & $672(36.0)$ & $220(29.1)$ & $<0.001^{* *}$ \\
\hline$<1$ & $642(42.5)$ & 251 (35.6) & & 1097 (58.8) & $507(67.0)$ & \\
\hline Unknown & $87(5.8)$ & $21(3.0)$ & & $97(5.2)$ & $30(4.0)$ & \\
\hline \multicolumn{7}{|l|}{ Mood } \\
\hline$<2$ & $911(60.4)$ & $502(71.0)$ & $<0.001^{* *}$ & $1008(54.0)$ & $500(66.1)$ & $<0.001^{* *}$ \\
\hline$\geq 2$ & $399(26.4)$ & $148(21.0)$ & & $563(30.2)$ & 179 (23.7) & \\
\hline Unknown & 199 (13.2) & $56(7.9)$ & & 295 (15.8) & 78 (10.3) & \\
\hline
\end{tabular}

IADL instrumental activities of daily living

${ }^{*}$-value $<0.05,{ }^{* *} p$-value $<0.001$

${ }^{a}$ Chi-square test was performed for categorical variables

${ }^{b}$ All unknown (missing) variables were included either merely missing or "no response" on purpose

may have attenuated the impact of this association in the current study. Qualitative research has found that possible barriers to the participation in physical activity programs include unavailability of access, cost, convenience of physical activity programs, and physical limitations due to health conditions [25]. The current results suggest that non-participants were more likely to reside in provincial area and men who were unlikely to use automobiles and thus could expect poor accessibility, thereby depriving them of the opportunity to participate in the physical checkup. These findings indicate that economic status impacts participation in health programs more for older Japanese men than for women.

Health consciousness, including self-rated health, interest in health topics, and smoking status may distract older people from acting out healthy behaviors (i.e., 
Table 3 The adjusted odds ratios for physical check-up non-participation per sociodemographic status variables among older men

\begin{tabular}{|c|c|c|c|}
\hline & Non-participation & Model $1^{c}$ & Model $2^{d}$ \\
\hline & / total, n (\%) & $\mathrm{aOR}(95 \% \mathrm{Cl})$ & $\mathrm{aOR}(95 \% \mathrm{Cl})$ \\
\hline \multicolumn{4}{|l|}{ Age (years) } \\
\hline $65-69$ & $519 / 745(69.7)$ & reference & reference \\
\hline $70-74$ & $411 / 608(67.6)$ & $0.88(0.69,1.12)$ & $0.88(0.69,1.12)$ \\
\hline $75-79$ & 297/453 (65.6) & $0.75(0.57,0.99)^{*}$ & $0.73(0.56,0.96)^{*}$ \\
\hline$\geq 80$ & $282 / 409(69.0)$ & $0.82(0.61,1.09)$ & $0.79(0.58,1.07)$ \\
\hline \multicolumn{4}{|l|}{ Social status } \\
\hline \multicolumn{4}{|l|}{ Family structure } \\
\hline With someone or others & 1292/1922 (67.2) & reference & reference \\
\hline Alone & $85 / 122(69.7)$ & $1.00(0.65,1.52)$ & $0.98(0.64,1.49)$ \\
\hline Unknown ${ }^{a}$ & 132/171 (77.2) & $1.39(0.93,2.06)$ & $1.33(0.89,1.99)$ \\
\hline \multicolumn{4}{|l|}{ Living with spouse $^{d}$} \\
\hline Yes & $413 / 612(67.5)$ & reference & reference \\
\hline No & 773/1184 (65.3) & $0.97(0.78,1.21)$ & $0.98(0.79,1.23)$ \\
\hline Unknown & 238/297 (80.1) & $1.92(1.12,3.29)^{*}$ & $1.91(1.11,3.28)^{*}$ \\
\hline \multicolumn{4}{|l|}{ Alone at home ${ }^{d}$} \\
\hline Rarely & 294/375 (78.4) & reference & reference \\
\hline Frequently & $896 / 1399(64.1)$ & $0.52(0.39,0.69)^{* *}$ & $0.53(0.40,0.70)^{* *}$ \\
\hline Unknown & 234/319 (73.4) & $0.53(0.33,0.83)^{*}$ & $0.53(0.33,0.83)^{*}$ \\
\hline \multicolumn{4}{|l|}{ Educational attainment (years) } \\
\hline$\geq 13$ & $334 / 545(61.3)$ & reference & reference \\
\hline $10-12$ & $541 / 838(64.6)$ & $1.04(0.83,1.32)$ & $1.04(0.82,1.31)$ \\
\hline$\leq 9$ & 407/544 (74.8) & $1.53(1.16,2.02)^{*}$ & $1.52(1.15,2.01)^{*}$ \\
\hline Unknown & 227/288 (78.8) & $1.85(1.30,2.65)^{*}$ & $1.74(1.21,2.50)^{*}$ \\
\hline \multicolumn{4}{|l|}{ Economic status } \\
\hline \multicolumn{4}{|l|}{ Economic difficulty } \\
\hline No & 440/697 (63.1) & reference & reference \\
\hline Yes & 1003/1431 (70.1) & $1.19(0.96,1.46)$ & $1.20(0.98,1.48)$ \\
\hline Unknown & 66/87 (75.9) & $1.34(0.76,2.39)$ & $1.31(0.73,2.32)$ \\
\hline \multicolumn{4}{|l|}{ Pension } \\
\hline National Pension & 970/1498 (64.8) & reference & reference \\
\hline Employees' Pension & 440/601 (73.2) & $1.32(1.05,1.65)^{*}$ & $1.30(1.04,1.63)^{*}$ \\
\hline Nothing or others & $57 / 66(86.4)$ & $1.96(0.93,4.11)$ & $2.01(0.96,4.23)$ \\
\hline Unknown & $42 / 50(84.0)$ & $1.78(0.76,4.18)$ & $1.88(0.80,4.42)$ \\
\hline \multicolumn{4}{|l|}{ Current employment } \\
\hline Working & $442 / 643(68.7)$ & reference & reference \\
\hline Not working & $949 / 1415$ (67.1) & $0.81(0.65,1.02)$ & $0.82(0.66,1.02)$ \\
\hline Unknown & 118/157 (75.2) & $0.90(0.58,1.41)$ & $0.87(0.56,1.36)$ \\
\hline \multicolumn{4}{|l|}{ Automobile access } \\
\hline Yes & $1214 / 1829(66.4)$ & reference & reference \\
\hline No & 295/386 (76.4) & $1.36(1.03,1.78)^{*}$ & $1.32(1.00,1.74)^{*}$ \\
\hline
\end{tabular}

Health conscious

Interest in health topics 
Table 3 The adjusted odds ratios for physical check-up non-participation per sociodemographic status variables among older men (Continued)

\begin{tabular}{|c|c|c|c|}
\hline & Non-participation & Model $1^{c}$ & Model $2^{d}$ \\
\hline & / total, n (\%) & $\mathrm{aOR}(95 \% \mathrm{Cl})$ & aOR (95\% Cl) \\
\hline No & $240 / 299(80.3)$ & $1.64(1.20,2.24)^{*}$ & $1.69(1.23,2.33)^{*}$ \\
\hline Unknown & 48/59 (82.0) & $2.00(1.01,4.00)^{*}$ & $1.69(0.83,3.43)$ \\
\hline \multicolumn{4}{|c|}{ Self-rated health } \\
\hline Good & 1097/1680 (65.3) & reference & reference \\
\hline Poor & $346 / 438(79.0)$ & $1.62(1.24,2.12)^{* *}$ & $1.68(1.27,2.22)^{* *}$ \\
\hline Unknown & 66/97 (68.0) & $0.66(0.33,1.35)$ & $0.63(0.31,1.28)$ \\
\hline \multicolumn{4}{|c|}{ Smoking status } \\
\hline Never & $329 / 492$ (66.9) & reference & reference \\
\hline Past & 794/1209 (65.7) & $0.98(0.78,1.24)$ & $0.98(0.78,1.24)$ \\
\hline Current & $316 / 415(76.1)$ & $1.63(1.19,2.21)^{*}$ & $1.62(1.19,2.21)^{*}$ \\
\hline Unknown & 70/99 (70.7) & $1.04(0.50,2.17)$ & $0.92(0.44,1.93)$ \\
\hline \multicolumn{4}{|c|}{ Community activities } \\
\hline Yes & $915 / 1458$ (62.8) & reference & reference \\
\hline No & $594 / 757(78.5)$ & $1.94(1.54,2.43)^{* *}$ & $1.94(1.54,2.44)^{* *}$ \\
\hline \multicolumn{4}{|c|}{ Population density } \\
\hline City & $534 / 830(64.3)$ & reference & reference \\
\hline Province & 975/1385 (70.4) & $1.19(0.98,1.44)$ & $1.20(0.99,1.46)$ \\
\hline
\end{tabular}

aOR $(95 \% \mathrm{Cl})$ adjusted odds ratios (95\% confidence interval)

" $P$-value $<0.05,{ }^{* * *} P$-value $<0.001$

aAll unknown (missing) variables were included either merely missing or "no response" on purpose.

Multiple logistic regression model was performed in Model 1 and Model 2

${ }^{\mathrm{b}}$ Model 1 , adjusted for age $(65-69,70-74,75-79$, and $\geq 80$ years), family structure (with someone or others, alone, unknown), educational attainment ( $\leq 9,10-12$, $\geq 13$, and unknown years), economic difficulties (yes, no, and unknown), pension (National Pension, Employees' Pension, others or nothing, and unknown), automobile access (yes / no), interest in health topics (yes, no, and unknown), self-rated health (good, poor, and unknown), smoking (never, past, current, and unknown), social participation (yes / no), and population density (city / province)

'Model 2, Model $1+$ total score of Kihon checklist $(<7, \geq 7$, and unknown)

${ }^{d}$ These results were indicated 2, 093 men among those who were 'living with someone or others' in the family structure.

participation in physical activity program). A similar trend was observed in prior research, in which a significant association emerged between poor self-rated health and lower attendance of a health checkup among Australians aged 20 years or older (population aged 65 years or older was $44.5 \%$ in men) [26]. An association between social participation and a high level of self-rated health has also been found previously [28]. Participation in a community based health program can be regarded as a type of social participation [28-30]. Thus, it could be that individuals with poor health consciousness have low motivation for social participation, and thus not participated in a physical checkup.

In a cross-sectional study, it was found that participation in community and social activities was significantly associated with engaging in physical fitness study [31]. Participants who engaged in a social activity had higher levels of locomotive function [31]. A longitudinal study also found that social participation among older Japanese people, including social activity, was associated with a lower risk of functional disability $[29,30]$. It may be that participants who do not participate in social activities hesitated to participate in the physical checkup due to their low level of physical functioning.

It has been reported that characteristics of participants differed from the strengths and the contents of physical activity programs (i.e., gardening or yard work, walking, and sports or exercise) according to gender and functional health [32]. Qualitative research also suggests that physical limitations due to health conditions were a potential barrier to participation in physical activity programs [25]. Literature reported the negative association between regular participation in sports groups and IADL level [14]. Indeed, our study found a significant association between participating in no community activities and being a nonparticipant. Although this study cannot determine causality, it links anxiety related to low physical function level to both lower participation in community activities and nonparticipation in physical checkups. In addition, aging, which was associated with frailty, may more predict nonparticipation in a physical checkup in women as compared to that in older men, according to the present results. It is said that older women get a muscle damage and low grip strength with aging more easily than older men [33]. 
Table 4 The adjusted odds ratios for physical check-up non-participation per sociodemographic status variables among older women

\begin{tabular}{|c|c|c|c|}
\hline & Non-participation & Model $1^{\mathrm{b}}$ & Model $2^{c}$ \\
\hline & / total n (\%) & $\mathrm{aOR}(95 \% \mathrm{Cl})$ & $\mathrm{aOR}(95 \% \mathrm{Cl})$ \\
\hline \multicolumn{4}{|l|}{ Age (years) } \\
\hline $65-69$ & $543 / 789(68.8)$ & reference & reference \\
\hline $70-74$ & $439 / 682(64.4)$ & $0.77(0.61,0.97)^{*}$ & $0.76(0.60,0.95)^{* *}$ \\
\hline $75-79$ & $387 / 560(69.1)$ & $0.88(0.68,1.13)$ & $0.84(0.65,1.09)$ \\
\hline$\geq 80$ & 490/585 (83.8) & $1.99(1.49,2.66)^{*}$ & $1.86(1.38,2.52)^{* *}$ \\
\hline \multicolumn{4}{|l|}{ Social status } \\
\hline \multicolumn{4}{|l|}{ Family structure } \\
\hline With someone or others & $1454 / 2048(71.1)$ & reference & reference \\
\hline Alone & $243 / 361(67.3)$ & $0.78(0.60,1.01)$ & $0.78(0.60,1.01)$ \\
\hline Unknown $^{a}$ & 162/207 (78.3) & $1.28(0.88,1.85)$ & $1.26(0.87,1.82)$ \\
\hline \multicolumn{4}{|l|}{ Living with spouse $^{d}$} \\
\hline Yes & $572 / 806(71.0)$ & reference & reference \\
\hline No & $770 / 1112(69.2)$ & $1.09(0.88,1.35)$ & $1.10(0.89,1.36)$ \\
\hline Unknown & 274/337 (81.3) & $2.30(1.33,3.97)^{*}$ & $2.31(1.33,3.97)^{*}$ \\
\hline \multicolumn{4}{|l|}{ Alone at home ${ }^{d}$} \\
\hline Rarely & $276 / 362(76.2)$ & reference & reference \\
\hline Frequently & 1078/1555 (69.3) & $0.67(0.51,0.88)^{*}$ & $0.67(0.50,0.88)^{*}$ \\
\hline Unknown & $262 / 338(77.5)$ & $0.92(0.56,1.51)$ & $0.92(0.56,1.52)$ \\
\hline \multicolumn{4}{|l|}{ Educational attainment (years) } \\
\hline$\geq 13$ & $270 / 401(67.3)$ & reference & reference \\
\hline $10-12$ & $793 / 1175$ (67.5) & $0.95(0.73,1.23)$ & $0.94(0.73,1.21)$ \\
\hline$\leq 9$ & $531 / 692(76.7)$ & $1.26(0.94,1.69)$ & $1.24(0.93,1.67)$ \\
\hline Unknown & 265/348 (76.2) & $1.05(0.73,1.49)$ & $1.00(0.70,1.44)$ \\
\hline \multicolumn{4}{|l|}{ Economic status } \\
\hline \multicolumn{4}{|l|}{ Economic difficulty } \\
\hline No & $585 / 857(68.3)$ & reference & reference \\
\hline Yes & 1156/1598 (72.3) & $1.18(0.97,1.44)$ & $1.18(0.97,1.43)$ \\
\hline Unknown & 118/161 (73.3) & $1.13(0.73,1.74)$ & $1.10(0.711 .70)$ \\
\hline \multicolumn{4}{|l|}{ Pension } \\
\hline Mutual or welfare & $537 / 777(69.1)$ & reference & reference \\
\hline National & 1163/1638 (71.0) & $1.05(0.87,1.29)$ & $1.05(0.86,1.28)$ \\
\hline Nothing or others & $93 / 110(84.6)$ & $1.49(0.84,2.65)$ & $1.47(0.83,2.61)$ \\
\hline Unknown & $66 / 91(72.5)$ & $0.98(0.56,1.72)$ & $0.98(0.56,1.72)$ \\
\hline \multicolumn{4}{|l|}{ Current employment } \\
\hline Working & 191/291 (65.6) & reference & reference \\
\hline Not working & $1485 / 2080(71.5)$ & $1.10(0.83,1.46)$ & $1.10(0.83,1.46)$ \\
\hline Unknown & $183 / 245(74.7)$ & $1.18(0.77,1.80)$ & $1.15(0.76,1.76)$ \\
\hline \multicolumn{4}{|l|}{ Automobile access } \\
\hline Yes & $1211 / 1730(70.0)$ & reference & reference \\
\hline No & $648 / 886(73.1)$ & $1.09(0.89,1.33)$ & $1.08(0.88,1.32)$ \\
\hline
\end{tabular}

Health conscious

Interest in health topics 
Table 4 The adjusted odds ratios for physical check-up non-participation per sociodemographic status variables among older women (Continued)

\begin{tabular}{|c|c|c|c|}
\hline & Non-participation & Model $1^{b}$ & Model $2^{c}$ \\
\hline & / total n (\%) & aOR $(95 \% \mathrm{Cl})$ & $\mathrm{aOR}(95 \% \mathrm{Cl})$ \\
\hline Yes & 1672/2394 (69.8) & reference & reference \\
\hline No & 140/161 (87.0) & $1.81(1.10,2.97)^{*}$ & $1.78(1.09,2.93)^{*}$ \\
\hline Unknown & 47/61 (77.1) & $1.10(0.58,2.10)$ & $1.04(0.54,1.99)$ \\
\hline \multicolumn{4}{|c|}{ Self-rated health } \\
\hline Good & 1396/2029 (68.8) & reference & reference \\
\hline Bad & $3987 / 484$ (80.0) & $1.19(0.92,1.55)$ & $1.14(0.87,1.50)$ \\
\hline Unknown & 76/103 (73.8) & $0.61(0.35,1.04)$ & $0.58(0.34,1.01)$ \\
\hline \multicolumn{4}{|c|}{ Smoking status } \\
\hline Never & $1547 / 2213(69,9)$ & reference & reference \\
\hline Past & 111/156 (71.2) & $0.98(0.67,1.44)$ & $0.99(0.68,1.45)$ \\
\hline Current & 87/101 (86.1) & $2.71(1.50,4.91)^{*}$ & $2.71(1.50,4.90)^{*}$ \\
\hline Unknown & $114 / 146(78.1)$ & $1.13(0.70,1.81)$ & $1.08(0.67,1.74)$ \\
\hline \multicolumn{4}{|c|}{ Community activities } \\
\hline Yes & 1062/1694 (62.7) & reference & reference \\
\hline No & $8797 / 922(86.4)$ & $3.34(2.66,4.20)^{* *}$ & $3.30(2.62,4.15)^{* *}$ \\
\hline \multicolumn{4}{|c|}{ Population density } \\
\hline City & $661 / 958(69.0)$ & reference & reference \\
\hline Province & 1198/1658 (72.3) & $1.08(0.90,1.31)$ & $1.07(0.89,1.29)$ \\
\hline
\end{tabular}

aOR $(95 \% \mathrm{Cl})$ adjusted odds ratios (95\% confidence interval)

" $P$-value $<0.05,{ }^{* *} P$-value $<0.001$

aAll unknown (missing) variables were included either merely missing or "no response" on purpose.

Multiple logistic regression model was performed in Model 1 and Model 2

${ }^{b}$ Model 1 , adjusted for age $(65-69,70-74,75-79$, and $\geq 80$ years), family structure (with someone or others, alone, unknown), educational attainment ( $\leq 9,10-12$,

$\geq 13$, and unknown years), economic difficulties (yes, no, and unknown), pension (National Pension, Employees' Pension, others or nothing, and unknown),

automobile access (yes / no), interest in health topics (yes, no, and unknown), self-rated health (good, poor, and unknown), smoke (never, past, current, and

unknown), social participation (yes / no), and population density (city / province)

${ }^{c}$ Model 2, Model $1+$ total score of Kihon check list ( $<7, \geq 7$, and unknown)

${ }^{d}$ These results were indicated 2,255 women among those who were 'living with someone or others' in the family structure.

These weaknesses of muscle with aging would hinder older women in participation of physical checkup. In the current study, it might have been hard for more frail individuals (as indicated by IADL and physical functioning/ strength) and frail women due to aging to engage in several tests of physical fitness over one hour. In addition, accessing the location of the program may have been difficult for frail individuals.

However, our findings are also inconsistent with some of those reported in previous studies. While we did not find a significant relationship between unemployment and participation, Yamakita et al. reported a significant association of unemployment with non-participation in sports activities [14]. However, while not statistically significant, among men in the study, the effect was in the same direction (i.e., unemployment predicting nonparticipation). Among women, limited number of participants who were 'working' in the current employment might result in the unclarified association. In our study, current mood was assessed by the KCL with 5 items, while Yamakita et al. assessed depression with the 15- item Geriatric Depression Scale-15 [14]. Therefore, differences in measurement may explain the different associations.

It should be noted that part of unknown variables were positively associated with the non-participation in this study. Although we could not clarify the reason, the missing variables may have a link with the latent background of non-participation.

The possible assessment of our findings could be described as below. Cornwell et al. indicate that social isolation consists of a lack of social support and feelings of loneliness [34, 35]. When older people feel loneliness due to poor sociodemographic status and physical frailty, fears of social participation may hinder their motivation to participate in a physical activity program. To prevent health inequality, it is necessary to enhance social support of non-participants so that they can have the opportunity to attend health programs.

The main strength of this study is that our findings indicated that poor sociodemographic status and physical frailty may cause non-participation, as the physical 
Table 5 The adjusted odds ratios of physical checkup nonparticipation per Kihon Checklist (KCL) scores in older men.

\begin{tabular}{lll}
\hline Non-participation & Model 1 ${ }^{\mathrm{b}}$ & Model $2^{\mathrm{c}}$ \\
/ total n (\%) & aOR (95\% Cl) & aOR (95\% Cl) \\
\hline
\end{tabular}

\begin{tabular}{lll}
\hline $\begin{array}{l}\text { Total KCL } \\
<7\end{array}$ & $671 / 1061(63.2)$ & reference \\
$\geq 7$ & $343 / 491(69.9)$ & $0.87(0.66,1.13)$ \\
Unknown & $495 / 663(74.7)$ & $1.26(0.96,1.64)$
\end{tabular}

IADL

$\begin{array}{llll}<3 & 1102 / 1705(64.6) & \text { reference } & \text { reference } \\ \geq 3 & 311 / 390(79.7) & 1.35(1.01,1.82)^{*} & 1.33(0.98,1.81) \\ \text { Unknown } & 96 / 120(80.0) & 1.60(0.84,3.04) & 1.37(0.70,2.66)\end{array}$

Physical function/strength

$\begin{array}{llll}<3 & 1075 / 1651(65.1) & \text { reference } & \text { reference } \\ \geq 3 & 262 / 336(78.0) & 1.40(1.03,1.91)^{*} & 1.41(1.02,1.95)^{*} \\ \text { Unknown } & 172 / 228(75.4) & 1.22(0.86,1.74) & 1.13(0.75,1.72)\end{array}$

Malnutrition

$\begin{array}{llll}<2 & 1225 / 1844(66.4) & \text { reference } & \text { reference } \\ 2 & 36 / 47(76.6) & 1.13(0.55,2.33) & 1.18(0.56,2.46) \\ \text { Unknown } & 248 / 324(76.5) & 1.24(0.91,1.69) & 1.21(0.87,1.68)\end{array}$

Oral function

$\begin{array}{llll}<2 & 1048 / 1578(66.4) & \text { reference } & \text { reference } \\ \geq 2 & 377 / 529(71.3) & 0.98(0.77,1.24) & 0.91(0.71,1.17) \\ \text { Unknown } & 84 / 108(77.8) & 1.08(0.65,1.81) & 0.80(0.45,1.44)\end{array}$

Socialization

$\begin{array}{llll}<1 & 960 / 1439(66.7) & \text { reference } & \text { reference } \\ \geq 1 & 487 / 695(70.1) & 0.85(0.68,1.06) & 0.76(0.60,0.96)^{*} \\ \text { Unknown } & 62 / 81(76.5) & 1.02(0.57,1.82) & 0.75(0.39,1.44)\end{array}$

Memory

$\begin{array}{llll}<1 & 780 / 1214(64.3) & \text { reference } & \text { reference } \\ \geq 1 & 642 / 893(71.9) & 1.13(0.93,1.39) & 1.10(0.90,1.36) \\ \text { Unknown } & 87 / 110(80.6) & 1.47(0.86,2.51) & 1.27(0.69,2.34) \\ \text { Mood } & & & \\ <2 & 911 / 1413(64.5) & \text { reference } & \text { reference } \\ \geq 2 & 399 / 547(72.9) & 1.11(0.87,1.42) & 1.12(0.86,1.45) \\ \text { Unknown } & 199 / 255(78.0) & 1.96(1.28,3.01)^{*} & 1.93(1.24,3.00)^{*}\end{array}$

$I A D L$ instrumental activities of daily living; aOR $(95 \% \mathrm{Cl})$, adjusted odds ratios (95\% confidence interval)

${ }^{*} P$-value $<0.05,{ }^{* *} P$-value $<0.001$

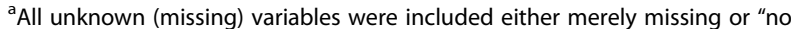
response" on purpose.

Multiple logistic regression model was performed in Model 1 and Model 2

${ }^{b}$ Model 1 , age $(65-69,70-74,75-79$, and $\geq 80$ years), family structure (with

someone or others, alone, and unknown), educational attainment $(\leq 9,10-12$, $\geq 13$, and unknown years), economic difficulties (yes, no, and unknown), pension (National Pension, Employees' Pension, others or nothing, and unknown), automobile access (yes / no), interest in health topics (yes, no, and unknown), self-rated health (good, poor, and unknown), smoke (never, past, current, and unknown), social participation (yes / no), and population density (city / province)

'Model 2, Model $1+7$ items of Kihon Checklist $(</ \geq$ with each cutoff point, and unknown)
Table 6 The adjusted odds ratios of physical checkup nonparticipation per Kihon Checklist (KCL) scores in older women

\begin{tabular}{llll}
\hline & Non-participation & Model $1^{\mathrm{b}}$ & Model 2 $^{\mathrm{c}}$ \\
& / total $\mathrm{n}(\%)$ & $\mathrm{aOR}(95 \% \mathrm{Cl})$ & $\mathrm{aOR}(95 \% \mathrm{Cl})$ \\
\hline Total KCL & & & \\
$<7$ & $725 / 1138(63.7)$ & reference & \\
$\geq 7$ & $467 / 595(78.5)$ & $1.14(0.87,1.49)$ & \\
Unknown & $667 / 883(75.5)$ & $1.21(0.95,1.53)$ &
\end{tabular}

IADL

$\begin{array}{llll}<3 & 1404 / 2098(67.0) & \text { reference } & \text { reference } \\ \geq 3 & 310 / 341(90.9) & 2.42(1.60,3.64)^{* *} & 2.28(1.50,3.46)^{* *} \\ \text { Unknown } & 145 / 177(81.9) & 1.79(1.11,2.89)^{*} & 1.63(0.99,2.67)\end{array}$

Physical function/strength

$\begin{array}{llll}<3 & 1075 / 1614(66.6) & \text { reference } & \text { reference } \\ \geq 3 & 555 / 694(80.0) & 1.36(1.07,1.73)^{*} & 1.28(1.00,1.65)^{*} \\ \text { Unknown } & 229 / 308(74.4) & 1.11(0.81,1.52) & 0.92(0.65,1.30)\end{array}$

Malnutrition

$\begin{array}{llll}<2 & 1466 / 2114(69.4) & \text { reference } & \text { reference } \\ 2 & 38 / 52(73.1) & 0.76(0.39,1.46) & 0.78(0.40,1.53) \\ \text { Unknown } & 355 / 450(78.9) & 1.32(1.00,1.74)^{*} & 1.25(0.93,1.67)\end{array}$

Oral function

$\begin{array}{llll}<2 & 1311 / 1887(69.5) & \text { reference } & \text { reference } \\ \geq 2 & 433 / 587(73.8) & 0.85(0.68,1.08) & 0.80(0.63,1.03) \\ \text { Unknown } & 115 / 142(81.0) & 1.33(0.83,2.13) & 1.16(0.69,1.94)\end{array}$

Socialization

$\begin{array}{llll}<1 & 995 / 1507(66.0) & \text { reference } & \text { reference } \\ \geq 1 & 788 / 1013(77.8) & 1.23(1.00,1.51) & 1.17(0.94,1.46) \\ \text { Unknown } & 76 / 96(79.2) & 1.47(0.84,2.58) & 1.42(0.78,2.59)\end{array}$

Memory

\begin{tabular}{llll}
$<1$ & $1095 / 1602(68.4)$ & reference & reference \\
$\geq 1$ & $668 / 888(75.2)$ & $0.98(0.80,1.20)$ & $0.92(0.75,1.14)$ \\
Unknown & $96 / 126(76.2)$ & $1.06(0.66,1.70)$ & $0.85(0.51,1.42)$ \\
Mood & & & \\
$<2$ & $1008 / 1508(66.8)$ & reference & reference \\
$\geq 2$ & $557 / 736(75.7)$ & $1.06(0.84,1.33)$ & $0.99(0.78,1.26)$ \\
Unknown & $294 / 372(79.0)$ & $1.29(0.92,1.81)$ & $1.15(0.81,1.64)$ \\
\hline
\end{tabular}

$I A D L$ instrumental activities of daily living; aOR $(95 \% \mathrm{Cl})$, adjusted odds ratios (95\% confidence interval)

${ }^{*} P$-value $<0.05,{ }^{* *} P$-value $<0.001$

${ }^{a}$ All unknown (missing) variables were included either merely missing or "no response" on purpose.

Multiple logistic regression model was performed in Model 1 and Model 2

bodel 1 , age (65-69, 70-74, 75-79, and $\geq 80$ years), family structure (with someone or others, alone, and unknown), educational attainment $(\leq 9,10-12$, $\geq 13$, and unknown years), economic difficulties (yes, no, and unknown), pension (National Pension, Employees' Pension, others or nothing, and unknown), automobile access (yes / no), interest in health topics (yes, no, and unknown), self-rated health (good, poor, and unknown), smoke (never, past, current, and unknown), social participation (yes / no), and population density (city / province)

${ }^{c}$ Model 2, Model $1+7$ items of Kihon Checklist $(</ \geq$ with each cutoff point and unknown) 
checkup was implemented with over a six-month time lag from the baseline survey.

Our study had several limitations. First, all eligible subjects were responders at the baseline survey ( $73.2 \%$ of total residents). This study cannot clarify associations between personal characteristics and non-participation for the types of individuals who did not respond to the baseline survey (26.8\% of total residents). Second, our sample was ascertained from a specific Japanese community, and our findings may not generalize to other older population. Third, we used a single arm for recruiting, and did not compare the different types of recruiting methods, which may be a confounding factor. Finally, there is a possibility that participants of physical checkup were authorized people (e.g, working staff, city officers, and their family or their relatives), which may be a confounding factor that describes the characteristics of participants. However, there were few authorized people and their impact on the results may be low. Because the impact of the number of research staffs on participation rates may low, we did not mention in the present study. The interesting finding that the participation rate in men was higher than in women may indicate a need to explore differences in recruiting methods and specifics of particular programs.

\section{Conclusions}

In conclusion, a poor sociodemographic background and physical frailty may predict non-participation in community based physical activity programs in community-dwelling older people. To develop a health program considering the role of social exchange may contribute to improve the participation rates. At the same time, we should build health program with considering the level of aging and physical frailty to increase the participation. To prevent health inequality, non-participants should have opportunity to receive social support to participate a community-based health program without barriers.

\section{Additional files}

Additional file 1 Table S1. Needs in the Sphere of Daily Life questionnaire. (DOCX $19 \mathrm{~kb}$ )

Additional file $\mathbf{2}$ Table S2. The Kihon-Checklist with 25 questions. (DOCX $20 \mathrm{~kb})$

\section{Abbreviations}

Cl: Confidence interval; aOR: Adjusted odds ratio; IADL: Instrumental activities of daily living; KCL: Kihon Checklist; NSDL: Needs in the Sphere of Daily Life; SD: Standard deviation

\section{Acknowledgements}

The authors thank all participants in this study and all staff of the Kameoka-Study Group. This study was partly based on data from the Kyoto-Kameoka Longitudinal Study database provided by The Promotion Organization of Integrated Community Care System of Kyoto Prefecture, Kyoto Dental Hygienists' Association, Kyoto Dietetic Association, and Kameoka City municipal government. We especially thank Mr. Masahiro Fukuda, Ms. Kazuko Ohkura, Ms. Haruka Nishioka, and Ms. Sairi Watanabe for their dedicated efforts. We also thank Prof. Tomoki Nakaya, Ritsumeikan University for his advice about study design.

\section{Funding}

This work was supported by MEXT KAKENHI research grants from JSPS (Grant Numbers 24240091 [to Misaka Kimura], 25750360 [to Yuya Watanabe], 23-333 and $15 \mathrm{H} 05363$ [to Yosuke Yamada]) and supported by a grant from the Promotion Organization of Integrated Community Care System of Kyoto Prefecture and a grant from the Kameoka City municipal government.

\section{Availability of data and materials}

Researchers can apply to the Kyoto-Kameoka Study Group for permission to use this data through the YY (yamaday@nibiohn.go.jo) or MK (misaka@kyotogakuen.ac.jp) on reasonable request.

\section{Authors' contributions}

MY designed research and performed statistical analysis and Y Yamada supervised study design. TY, Y Yamada, YW, and HN conducted research coordination, data curation, and supported the study design; TY, Y Yamada, YW, KY, MM, Al, EY, YO, Y Yoshinaka, MK conducted data collection. TY, Y Yamada, YW, $\mathrm{HN}, \mathrm{HD}, \mathrm{Al}, \mathrm{TM}$ conducted data cleaning of mail survey; MK and $\mathrm{YY}$ developed Kyoto-Kameoka study protocols and fund acquisition; all authors revised and/or approved the final manuscript.

\section{Ethics approval and consent to participate}

The entire study protocol was reviewed and approved by the Ethics Committee of Kyoto Prefectural University of Medicine (RBMR-E-371 and 372) and the National Institute of Health and Nutrition (NIHN187-3). This study is registered with the University hospitals Medical Information Network Center - Clinical Trials Registration database (UMIN000008105) abiding by Helsinki Declaration. All participants provided written informed consent before undergoing this study.

\section{Competing interests}

The authors declare that they have no competing interests.

\section{Publisher's Note}

Springer Nature remains neutral with regard to jurisdictional claims in published maps and institutional affiliations.

\section{Author details}

${ }^{1}$ Department of Nutrition and Metabolism, National Institutes of Biomedical Innovation, Health and Nutrition, Tokyo 162-8636, Japan. ${ }^{2}$ Senior Citizen's Welfare Section, Kameoka City Government, Kyoto 621-8501, Japan. ${ }^{3}$ Laboratory of Applied Health Sciences, Kyoto Prefectural University of Medicine, Kyoto 602-8566, Japan. ${ }^{4}$ Faculty of Economics and Business Administration, Kyoto Gakuen University, Kyoto 621-8555, Japan. ${ }^{5}$ Faculty of Health and Sports Science, Doshisha Unviersity, Kyoto 610-0394, Japan. ${ }^{6}$ Department of Health and Sports Sciences, Kyoto Gakuen University, Kyoto 621-8555, Japan. ${ }^{7}$ Faculty of Data Science, Shiga University, Shiga 522-8522, Japan. ${ }^{8}$ Department of Health, Sports and Nutrition, Faculty of Health and Welfare, Kobe Women's University, Hyogo 650-0046, Japan. ${ }^{9}$ Faculty of Nursing, Doshisha Women's College of Liberal Arts, Kyoto 610-0395, Japan.

Received: 3 July 2017 Accepted: 10 April 2018

Published online: 02 May 2018

\section{References}

1. Statistics Bureau Ministry of Internal Affairs and Communications: statistical handbook of Japan 2016. Available from http://www.stat.go.jp/english/data/ handbook/pdf/2016all.pdf. Accessed 13 Apr 2018.

2. Japan Ministry of Health Labour and Welfare: The manuals of the evaluation for ability to perform daily activities on preventive care. 2009. Available from http://www.mhlw.go.jp/topics/2009/05/dl/tp0501-1c_0001.pdf. Accessed 13 Apr 2018. [Japanese]

3. Chernoff R. Nutrition and health promotion in older adults. J Gerontol A Biol Sci Med Sci. 2001;56:47-53.

4. Golinowska S, Groot W, Baji P, Pavlova M. Health promotion targeting older people. BMC Health Serv Res. 2016;16:345. 
5. Zubala A, MacGillivray S, Frost $H$, Kroll T, Skelton DA, Gavine A, et al. Promotion of physical activity interventions for community dwelling older adults: a systematic review of reviews. PLoS One. 2017;12:e0180902.

6. Ip EH, Church T, Marshall SA, Zhang Q, Marsh AP, Guralnik J, et al. Physical activity increases gains in and prevents loss of physical function: results from the lifestyle interventions and independence for elders pilot study. J Gerontol A Biol Sci Med Sci. 2013;68:426-32.

7. Mountain G, Windle G, Hind D, Walters S, Keertharuth A, Chatters R, et al. A preventative lifestyle intervention for older adults (lifestyle matters): a randomised controlled trial. Age Ageing. 2017:46:627-34.

8. Rejeski WJ, Marsh AP, Chmelo E, Prescott AJ, Dobrosielski M, Walkup MP, et al. The lifestyle interventions and independence for elders pilot (LIFE-P): 2-year follow-up. J Gerontol A Biol Sci Med Sci. 2009;64:462-7.

9. Clark F, Jackson J, Carlson M, Chou CP, Cherry BJ, Jordan-Marsh M, et al. Effectiveness of a lifestyle intervention in promoting the well-being of independently living older people: results of the well elderly 2 randomised controlled trial. J Epidemiol Community Health. 2012;66:782-90.

10. Yoshizawa Y, Kim J, Kuno S. Effects of a lifestyle-based physical activity intervention on medical expenditure in Japanese adults: a communitybased retrospective study. Biomed Res Int. 2016;2016:7530105.

11. van der Deijl M, Etman A, Kamphuis CB, van Lenthe FJ. Participation levels of physical activity programs for community-dwelling older adults: a systematic review. BMC Public Health. 2014;14:1301.

12. Liljas AEM, Jovicic A, Kharicha K, lliffe S, Manthorpe J, Goodman C, et al. Facilitators and barriers for recruiting and engaging hard-to-reach older people to health promotion interventions and related research: a systematic review. Lancet. 2015;386:S51.

13. Liljas AEM, Walters K, Jovicic A, lliffe S, Manthorpe J, Goodman C, et al. Strategies to improve engagement of 'hard to reach' older people in research on health promotion: a systematic review. BMC Public Health. 2017;17:349.

14. Yamakita M, Kanamori S, Kondo N, Kondo K. Correlates of regular participation in sports groups among Japanese older adults: JAGES crosssectional study. PLoS One. 2015;10:e0141638.

15. The official map of Kameoka City. Available from http://www.city.kameoka. kyoto.jp/kcm/kouzuihazado/top.html. Accessed 13 Apr 2018.

16. Yamada $Y$, Nanri H, Watanabe $Y$, Yoshida T, Yokoyama $K$, Itoi A, et al. Prevalence of frailty assessed by fried and Kihon checklist indexes in a prospective cohort study: design and demographics of the Kyoto-Kameoka longitudinal study. J Am Med Dir Assoc. 2017;18:733.e7-733.e15.

17. Kameoka City office: Population by Age, Sex - Total population in Kameoka city, Kyoto prefecture, Japan, July 1, 2011. Available from http://www.city. kameoka.kyoto.jp/uketsuke/shise/toke/jinko/h23701nenre.html. Accessed 13 Apr 2018. [Japanese]

18. Berkman L, Kawachi I, Glymour M. Social Epidemiology. 2nd ed. New York: Oxford University Press; 2014

19. National Pension System. Japan Pension Service register. Available from http://www.nenkin.go.jp/international/english/nationalpension/ nationalpension.html. Accessed 13 Apr 2018.

20. Fukutomi E, Okumiya $K$, Wada $T$, Sakamoto $R$, Ishimoto $Y$, Kimura $Y$, et al. Relationships between each category of 25-item frailty risk assessment (Kihon checklist) and newly certified older adults under long-term care insurance: a 24-month follow-up study in a rural community in Japan. Geriatr Gerontol Int. 2015;15:864-71.

21. Tomata Y, Watanabe T, Sugawara Y, Chou WT, Kakizaki M, Tsuji I. Dietary patterns and incident functional disability in elderly Japanese: the Ohsaki cohort 2006 study. J Gerontol A Biol Sci Med Sci. 2014;69:843-51.

22. Sewo Sampaio PY, Sampaio RA, Yamada M, Arai H. Systematic review of the Kihon checklist: is it a reliable assessment of frailty? Geriatr Gerontol Int. 2016;16:893-902.

23. Sewo Sampaio PY, Sampaio RAC, Yamada M, Arai H. Comparison of frailty between users and nonusers of a day care center using the Kihon checklist in Brazil. J Clin Gerontol Geriatr. 2014;5:82-5.

24. Yamada M, Arai H, Nishiguchi S, Kajiwara Y, Yoshimura K, Sonoda T, et al. Chronic kidney disease (CKD) is an independent risk factor for long-term care insurance ( $\mathrm{LTCl}$ ) need certification among older Japanese adults: a two-year prospective cohort study. Arch Gerontol Geriatr. 2013;57:328-32.

25. Bethancourt HJ, Rosenberg DE, Beatty T, Arterburn DE. Barriers to and facilitators of physical activity program use among older adults. Clin Med Res. 2014;12:10-20.
26. Brunner-Ziegler S, Rieder A, Stein KV, Koppensteiner R, Hoffmann K, Dorner TE. Predictors of participation in preventive health examinations in Austria. BMC Public Health. 2013;13:1138.

27. Hoebel J, Richter M, Lampert T. Social status and participation in health checks in men and women in Germany: results from the German health update (GEDA), 2009 and 2010. Dtsch Arztebl Int. 2013;110:679-85.

28. Ichida Y, Hirai H, Kondo K, Kawachi I, Takeda T, Endo H. Does social participation improve self-rated health in the older population? A quasiexperimental intervention study. Soc Sci Med. 2013;94:83-90.

29. Ashida T, Kondo N, Kondo K. Social participation and the onset of functional disability by socioeconomic status and activity type: the JAGES cohort study. Prev Med. 2016;89:121-8.

30. Kanamori S, Kai Y, Aida J, Kondo K, Kawachi I, Hirai H, et al. Social participation and the prevention of functional disability in older Japanese: the JAGES cohort study. PLoS One. 2014;9:e99638.

31. Haeuchi Y, Honda T, Chen T, Narazaki K, Chen S, Kumagai S. Association between participation in social activity and physical fitness in communitydwelling older Japanese adults. Nihon Koshu Eisei Zasshi. 2016;63:727-37.

32. Haley C, Andel R. Correlates of physical activity participation in communitydwelling older adults. J Aging Phys Act. 2010;18:375-89.

33. Hubbard RE, Rockwood K. Frailty in older women. Maturitas. 2011;69:203-7.

34. Cohen-Mansfield J, Hazan H, Lerman Y, Shalom V. Correlates and predictors of loneliness in older-adults: a review of quantitative results informed by qualitative insights. Int Psychogeriatr. 2016;28:557-76.

35. Cornwell EY, Waite L. Measuring social isolation among older adults using multiple indicators from the NSHAP study. J Gerontol B Psychol Sci Soc Sci. 2009;64:138-46.

\section{Ready to submit your research? Choose BMC and benefit from:}

- fast, convenient online submission

- thorough peer review by experienced researchers in your field

- rapid publication on acceptance

- support for research data, including large and complex data types

- gold Open Access which fosters wider collaboration and increased citations

- maximum visibility for your research: over $100 \mathrm{M}$ website views per year

At BMC, research is always in progress.

Learn more biomedcentral.com/submissions 